EXTENDED REPORT

\title{
Assessment of inflammatory activity in rheumatoid arthritis: a comparative study of clinical evaluation with grey scale and power Doppler ultrasonography
}

\author{
E Naredo, G Bonilla, F Gamero, J Uson, L Carmona, A Laffon
}

Ann Rheum Dis 2005;64:375-381. doi: 10.1136/ard.2004.023929

See end of article for authors' affiliations

Correspondence to: Dr E Naredo, Calle Arturo Soria 259, $4^{\circ} \mathrm{A}, 28033$ Madrid, Spain; esnaredo@ eresmas.com

Accepted 16 July 2004

\begin{abstract}
Objective: To compare the clinical assessment of overall inflammatory activity in patients with rheumatoid arthritis (RA) with grey scale and power Doppler (PD) ultrasonography (US).

Methods: Ninety four consecutive patients with RA were included. Demographic and clinical data, C reactive protein (CRP) level, and erythrocyte sedimentation rate (ESR) were recorded for each patient. The presence of tenderness, swelling, and a subjective swelling score from 1 to 3 were independently assessed by two rheumatologists, who reached a consensus in 60 joints examined in each patient. All patients underwent a US examination by a third blinded rheumatologist, using PD. US joint effusion, synovitis, and PD signal were graded from 1 to 3 in the 60 joints. Joint count and joint index for effusion, synovitis, and PD signal were recorded. A 28 joint count for clinical and US variables was calculated. Interobserver reliability of the US examination was evaluated by a fourth blinded rheumatologist.

Results: US showed significantly more joints with effusion (mean 15.2) and synovitis (mean 14.6) than clinical examination (mean 11.5, $\mathrm{p}<0.05$ ). A significant correlation was found between joint count and joint index for swelling, US effusion, synovitis, and PD signal. The 28 joint count for effusion, synovitis, and PD signal correlated highly with the corresponding 60 joint counts. US findings correlated better with CRP and ESR than clinical measures. Interobserver reliability was better for US findings than for clinical assessment.

Conclusion: US is a sensitive method for assessing joint inflammatory activity in RA, complementary to clinical evaluation.
\end{abstract}

$\mathrm{R}$ heumatoid arthritis (RA) is a chronic inflammatory disease characterised by the development of synovitis, which damages cartilage, bone, ligaments, and tendons. Assessment of inflammatory activity is essential in daily practice to enable therapeutic decisions and to evaluate disease outcome and response to treatment. ${ }^{1}$

Traditionally, the degree of disease activity has been evaluated by measuring subjective clinical variables, laboratory measures, and radiographic findings. ${ }^{2-4}$ However, clinical evaluation of joint pain and swelling have not been sufficiently reliable, ${ }^{5}$ and conventional plain radiography depicts indirect signs of cartilage loss and bony erosions due to previous destructive synovial inflammatory activity.

High frequency ultrasonography (US) has greatly improved musculoskeletal imaging in rheumatology. ${ }^{6}$ Several studies have demonstrated that high frequency US is accurate for detecting joint effusion ${ }^{7-16}$ and synovitis, ${ }^{7-11} 15$ 17-19, compared with magnetic resonance imaging (MRI) $)^{10} 1214$ and direct arthroscopic visualisation. ${ }^{20-22}$ US is more sensitive and reproducible than clinical evaluation in assessing joint inflammation. ${ }^{23-26}$

Power Doppler (PD) US is a new technique of colour Doppler that improves the sensitivity to detect flow from small vessels and low velocity flow at the microvascular level. ${ }^{27}{ }^{28}$ PD US detects indirect signs of increased vascularisation associated with soft tissue musculoskeletal inflammatory and infectious diseases, ${ }^{28}{ }^{29}$ and enthesitis in spondyloarthropathies..$^{30}$ The PD signal correlates highly with local clinical evaluation of joint inflammatory activity in the knee, metacarpophalangeal (MCP) and interphalangeal joints of patients with RA and other inflammatory arthropathies. $^{31}{ }^{32}$ Recent studies have shown that PD synovial vascularity correlates highly with histologically proved knee pannus $^{33}$ and with the degree of synovial vascularisation of the knee ${ }^{34}$ and hip. ${ }^{35}$

This study aimed at comparing grey scale US and PD US with clinical and biological findings in the determinination of global inflammatory activity assessed in 60 joints of patients with RA. To the best of our knowledge, this is the first US and clinical study that has examined so many joints in each patient with RA.

\section{PATIENTS AND METHODS}

Ninety four consecutive patients (20 male, 74 female) who fulfilled the 1987 American Rheumatism Association criteria for $\mathrm{RA}^{36}$ attending the outpatient rheumatology clinic were included. Mean (SD) age was 57.6 (14.3) years (range 23-88) and mean (SD) disease duration was 69.3 (58.2) months (range 5-280). Patients who had had traumatic, septic, or microcrystalline arthritis, previous joint surgery, or isotopic synovectomy within the past 12 months before the study were excluded.

The following data were recorded for each patient: age, sex, disease duration, drugs received for RA at entry, rheumatoid factor (measured by nephelometry, normal level 0-20 IU/ml), and previous joint surgery or isotopic synovectomy. $\mathrm{C}$ reactive protein (CRP) level (measured by nephelometry, normal range $0-8 \mathrm{mg} / \mathrm{l}$ ) and erythrocyte sedimentation rate (ESR;

\footnotetext{
Abbreviations: CRP, $C$ reactive protein; $E S R$, erythrocyte sedimentation rate; $H A Q$, Health Assessment Questionnaire; MCP,

metacarpophalangeal; $\mathrm{MRI}$, magnetic resonance imaging; $\mathrm{PD}$, power Doppler; PIP, proximal interphalangeal; PRF, pulse repetition frequency; RA, rheumatoid arthritis; SJC, swollen joint count; SJI, swollen joint index; TJC, tender joint count; US, ultrasonography; VASOA, visual analogue scale for patient overall assessment of disease activity; VASP, global pain intensity visual analogue scale
} 


\begin{tabular}{|c|c|}
\hline Joint & Criteria of effusion/synovitis \\
\hline Glenohumeral & $\begin{array}{l}\text { Posterior recess, transducer transverse to the humerus, shoulder in neutral } \\
\text { position: maximum distance from the posterior labrum to the posterior } \\
\text { infraspinatus and teres minor tendon (posterior capsule) }>3 \mathrm{~mm}\end{array}$ \\
\hline $\begin{array}{l}\text { Acromioclavicular and } \\
\text { sternoclavicular }\end{array}$ & $\begin{array}{l}\text { Transducer longitudinal to the joint: maximum distance from the articular bony } \\
\text { margin to the joint capsule }>3 \mathrm{~mm}\end{array}$ \\
\hline Elbow & $\begin{array}{l}\text { Longitudinally from the anterior recess with the joint in extension: maximum } \\
\text { distance from the humeral capitelum or the coronoid fossa to the joint capsule } \\
>2 \mathrm{~mm}\end{array}$ \\
\hline Wrist & $\begin{array}{l}\text { Longitudinally from the dorsal aspect with the joint in neutral position: maximum } \\
\text { distance from the bones to the joint capsule }>2 \mathrm{~mm}\end{array}$ \\
\hline MCP and PIP joints of hands & $\begin{array}{l}\text { Longitudinally from the dorsal view with the joint in extension: maximum distance } \\
\text { from the articular bony margin to the joint capsule }>2 \mathrm{~mm}\end{array}$ \\
\hline Hip & $\begin{array}{l}\text { Anterior recess, transducer longitudinal to the femoral neck, with the joint in } \\
\text { neutral position: maximum distance from the cortex, at the middle of the concavity } \\
\text { of the femoral neck to the joint capsule }>7 \mathrm{~mm} \text { or loss of concavity of the joint } \\
\text { capsule }\end{array}$ \\
\hline Knee & $\begin{array}{l}\text { Longitudinally from the suprapatellar recess, in a supine position, with the joint in } \\
30^{\circ} \text { of flexion: maximum anterior-posterior diameter of the suprapatellar bursa } \\
>3 \mathrm{~mm}\end{array}$ \\
\hline Ankle & $\begin{array}{l}\text { Longitudinally from the anterior recess with the joint in slight plantar flexion: } \\
\text { maximum distance from the talar bone to the joint capsule }>2 \mathrm{~mm}\end{array}$ \\
\hline Subtalar & $\begin{array}{l}\text { Longitudinally to the joint with the ankle in slight plantar flexion: maximum } \\
\text { distance from the articular bony margin to the joint capsule }>2 \mathrm{~mm}\end{array}$ \\
\hline Mid-tarsal & $\begin{array}{l}\text { Longitudinally from the dorsal view: maximum distance from the articular bony } \\
\text { margin to the joint capsule }>2 \mathrm{~mm}\end{array}$ \\
\hline MTP and PIP of feet & $\begin{array}{l}\text { Longitudinally from the dorsal view with the joints in extension: maximum distance } \\
\text { from the articular bony margin to the joint capsule }>2 \mathrm{~mm}\end{array}$ \\
\hline
\end{tabular}

measured by the Westergren method, VESMATIC 60, version 2.05; Menarini Laboratory, Barcelona, Spain) were recorded from each patient's routine laboratory test performed within 1 week of the study. Informed consent was obtained from all patients before the clinical and US evaluation.

\section{Clinical assessment}

The clinical evaluation was performed independently and sequentially by two blinded rheumatologists. One week before the study they carried out a consensus joint examination in patients with RA (not included in the study) for 20 hours. The following bilateral joints were assessed for tenderness and swelling: glenohumeral, acromioclavicular, sternoclavicular, elbow, wrist, MCP, proximal interphalangeal (PIP) of hands, knee, ankle, (tibiotalar), subtalar, midtarsal, metatarsophalangeal, and PIP of feet (total in 94 patients 5640 joints). Hip joints were assessed for tenderness and pain on passive motion. Hip swelling was indirectly considered if pain on passive motion was detected by physical examination. A subjective score from 1 to 3 was assigned for all swollen joints except for the hip $(1=$ mild; 2 moderate; $3=$ marked). Immediately after physical examination, GB and FG compared their findings. If there were discrepancies for the presence or absence of joint tenderness and swelling or the swollen joint scores, they carried out a third examination together to reach consensus. These last results were compared with US findings. Individual physical examinations were used for estimating clinical interobserver agreement for tenderness, swelling and swelling scores. Tender joint count (TJC), swollen joint count (SJC), and a 60 swollen joint index (SJI; sum of the swelling score from each joint) were recorded for each patient.

The following clinical variables were also recorded: a global pain intensity visual analogue scale (VASP; 0-100 mm), a visual analogue scale for patient overall assessment of disease activity (VASOA; 0-100 mm), and a self assessment Spanish version of the Health Assessment Questionnaire (HAQ). ${ }^{37}$

\section{US examination}

All patients underwent a US examination within 30 minutes of the clinical evaluation by a single rheumatologist experienced in US (EN) who was unaware of the clinical findings. US examination was performed with two commercially available ultrasound real time scanners (Logiq 400CL,
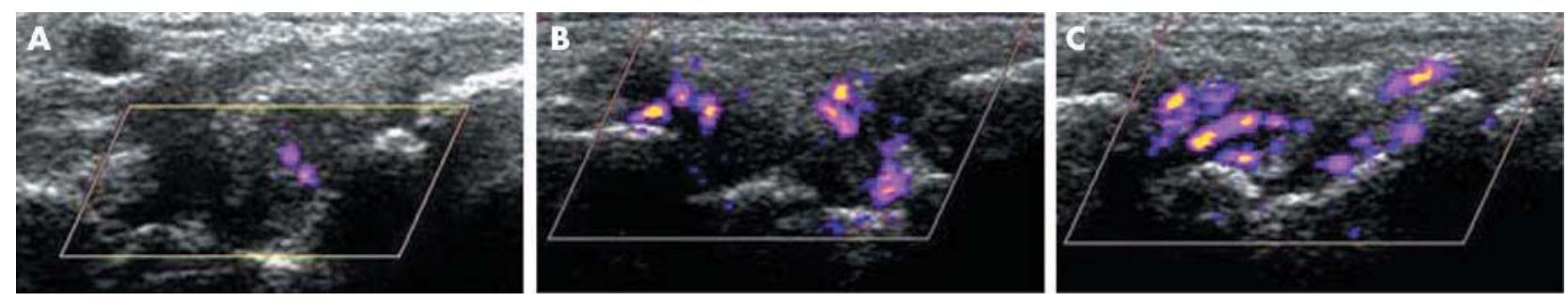

Figure 1 Longitudinal sonographic image of the wrist joint with moderate effusion, moderate synovitis, and mild (A), moderate (B), and marked (C) colour signal. 
Table 2 Demographic, clinical, and laboratory characteristics of patients evaluated with scanners 1 and 2

\begin{tabular}{llll}
\hline Characteristics & $\begin{array}{l}\text { Scanner } \mathbf{1} \\
(\mathbf{n = 6 9 )}\end{array}$ & $\begin{array}{l}\text { Scanner 2 } \\
(\mathbf{n}=\mathbf{2 5})\end{array}$ & $\mathbf{p}$ Value \\
\hline Age (years) & $58.1(14.3)$ & $56.3(14.3)$ & NS \\
Disease duration (months) & $68.3(57.9)$ & $72.2(60.1)$ & NS \\
Pain by 0-100 VAS (mm) & $30.5(26)$ & $36.3(30.3)$ & NS \\
Patient's overall assessment by 0-100 VAS (mm) & $38.2(26.1)$ & $38.3(28.6)$ & NS \\
Tender joint count & $14(16.1)$ & $9.8(13)$ & NS \\
Swollen joint count & $10.9(7.8)$ & $13.2(6.3)$ & NS \\
Swollen joint index & $69.8(9.7)$ & $72.6(8.4)$ & NS \\
Health Assessment Questionnaire score (0-3) & $1(0.7)$ & $0.9(0.7)$ & NS \\
Erythrocyte sedimentation rate (mm/1 st h) & $28.4(19.4)$ & $25.9(14.5)$ & NS \\
C reactive protein (mg/l) & $15(19)$ & $16(15)$ & NS \\
\hline Results are expressed as mean (standard deviation). & & & \\
VAS, visual analogue scale; NS, non-significant. & & & \\
\hline
\end{tabular}

General Electric Medical Systems, Korea (scanner 1) and Logiq 700, General Electric Medical Systems, Waukesha, WI, USA (scanner 2)) using multifrequency linear array transducers, $6-13 \mathrm{MHz}$ and 5-10 MHz, respectively, operating at 6.6 and $5 \mathrm{MHz}$ of frequency for Doppler imaging, respectively, according to the manufacturer's criteria. The first 69 patients were examined with scanner 1 and the last 25 patients with scanner 2. The presence of joint effusion and synovitis was systematically evaluated by US in each of the 60 joints clinically examined. Table 1 describes the US scanning method. The presence of effusion and/or synovitis was diagnosed in each joint according to the criteria listed in table 1. ${ }^{7-9}{ }^{12-14} 211^{38-40}$ Distances were measured using electronic callipers. Effusion and synovitis were identified and distinguished according to the following definitions. Effusion was defined as hypoechoic or anechoic compressible intraarticular material, within synovial recesses. Synovitis was defined as echogenic non-compressible intra-articular tissue, within synovial recesses. Joint effusion and synovitis were subjectively graded from 1 to 3 ( $1=$ mild; 2 =moderate; $3=$ marked) .

Synovial vascularisation was assessed by PD US in each of the 60 joints. PD imaging was performed by selecting a region of interest that included the bony margins, articular space, and a variable view of surrounding tissues (depending on the joint size). PD variables were adjusted to the lowest permissible pulse repetition frequency (PRF) to maximise sensitivity. This setting resulted in a PRF between 500 and
$1000 \mathrm{~Hz}$ depending on the joint scanned. Low wall filters were used. The dynamic range was 20-40 dB. Colour gain was set just below the level at which colour noise appeared underlying bone (no flow should be visualised at the bony surface). This setting resulted in gains of from 18 to $30 \mathrm{~dB}$. An image with maximal colour activity was selected for analysis. Flow was additionally demonstrated in two planes and confirmed by pulsed wave Doppler spectrum to exclude artefacts.

The intra-articular PD signal was subjectively graded on a semiquantitative scale from 0 to $3(0=$ absence, no intraarticular flow; $1=$ mild, single vessel signal; $2=$ moderate, confluent vessels; $3=$ marked, vessel signals in more than half of the intra-articular area). In each patient we recorded joint count for US effusion (USJCE), joint count for synovitis (USJCS), joint count for PD signal (USJCPD), and a 60 joint index for effusion (USJIE), synovitis (USJIS), and PD signal (USJIPD) (sum of the effusion, synovitis, and PD signal scores, respectively, obtained from each joint). In addition, we calculated for each patient a 28 joint count ( 10 PIP joints of hands, 10 MCP joints, 2 wrist, 2 elbow, 2 shoulder, 2 knee joints $)^{41}$ for tenderness (TJC28), swelling (SJC28), US effusion (USJCE28), US synovitis (USJCS28), and US PD signal (USJCPD28).

Inter- and intraobserver reliability of the US examination was evaluated by recording standard images of the 30 right joints from the first 22 patients evaluated with scanner 1 and the first 22 patients examined with scanner 2 in a digital

Table 3 Correlation between clinical, ultrasonographic, and laboratory variables

\begin{tabular}{llllll}
\hline & HAQ & VASP & VASOA & ESR & CRP \\
\hline TJC & $0.40^{*}$ & $0.46^{*}$ & $0.36^{*}$ & 0.12 & 0.08 \\
SJC & $0.44^{*}$ & $0.41^{*}$ & $0.33^{*}$ & $0.41^{*}$ & $0.51^{*}$ \\
SJ & $0.42^{*}$ & $0.39^{*}$ & $0.32^{*}$ & $0.45^{*}$ & $0.57^{*}$ \\
TJC28 & $0.42^{*}$ & $0.48^{*}$ & $0.39^{*}$ & 0.10 & 0.08 \\
SJC28 & $0.38^{*}$ & $0.35 \dagger$ & $0.29 \dagger$ & $0.39^{*}$ & $0.51^{*}$ \\
USJCE & 0.13 & $0.23 \dagger$ & $0.31^{*}$ & $0.50^{*}$ & $0.62^{*}$ \\
USJCS & 0.15 & $0.26 \dagger$ & $0.32^{*}$ & $0.50^{*}$ & $0.63^{*}$ \\
USJCPD & 0.12 & 0.18 & $0.23 \dagger$ & $0.45^{*}$ & $0.62^{*}$ \\
USJCE28 & 0.16 & $0.25 \dagger$ & $0.32^{*}$ & $0.49^{*}$ & $0.57^{*}$ \\
USJCS28 & 0.17 & $0.30^{*}$ & $0.36^{*}$ & $0.48^{*}$ & $0.60^{*}$ \\
USJCPD28 & 0.16 & $0.25 \dagger$ & $0.29^{*}$ & $0.50^{*}$ & $0.63^{*}$ \\
USJIE & 0.12 & $0.23 \dagger$ & $0.31^{*}$ & $0.51^{*}$ & $0.64^{*}$ \\
USJIS & 0.15 & $0.27^{*}$ & $0.32^{*}$ & $0.51^{*}$ & $0.64^{*}$ \\
USJIPD & 0.11 & 0.20 & 0.24 & $0.44^{*}$ & $0.63^{*}$ \\
\hline
\end{tabular}

${ }^{*} \mathrm{p}<0.01 ;+\mathrm{p}<0.05$

$\mathrm{HAQ}$, Health Assessment Questionnaire; VASP, visual analogue scale for pain; VASOA, visual analogue scale for patient's overall assessment; ESR, erythrocyte sedimentation rate; CRP, C reactive protein; TJC, tender joint count; SJC, swollen joint count; SJI, swollen joint index; USJCE, ultrasonographic joint count for effusion; USJCS, ultrasonographic joint count for synovitis; USJCPD, ultrasonographic joint count for power Doppler signal; USJIE, ultrasonographic joint index for effusion; USJIS, ultrasonographic joint index for synovitis; USJIPD, ultrasonographic joint index for power Doppler signal. 
Table 4 Correlation between clinical, ultrasonographic, and laboratory variables in patients evaluated with scanner 1

\begin{tabular}{llllll}
\hline & HAQ & VASP & VASOA & ESR & CRP \\
\hline USJCE & $0.29 \dagger$ & $0.36^{*}$ & $0.45^{*}$ & $0.59^{*}$ & $0.67^{*}$ \\
USJCS & $0.31^{*}$ & $0.38^{*}$ & $0.46^{*}$ & $0.59^{*}$ & $0.69^{*}$ \\
USJCPD & $0.34^{*}$ & $0.31 \dagger$ & $0.39^{*}$ & $0.61^{*}$ & $0.70^{*}$ \\
USJIE & $0.27 \dagger$ & $0.36^{*}$ & $0.46^{*}$ & $0.61^{*}$ & $0.71^{*}$ \\
USJIS & $0.30 \dagger$ & $0.40^{*}$ & $0.48^{*}$ & $0.61^{*}$ & $0.72^{*}$ \\
USJIPD & $0.31^{*}$ & $0.31^{*}$ & $0.40^{*}$ & $0.59^{*}$ & $0.74^{*}$ \\
\hline * $p<0.01 ;$ t $p<0.05$ & & & \\
For abbreviations see the footnote to table 3. & & & \\
\end{tabular}

archiving computer system. The saved images were blindly read by the same rheumatologist who performed US examination (EN) 3 months after the initial scanning, and by a fourth rheumatologist (JU) trained in US. These images did not show measurements. Before the study the investigators reached a consensus about the US scales. Figure 1 shows some examples of the US findings.

\section{Statistical analysis}

A $\chi^{2}$ test was applied for comparing cumulative variables, and Student's $t$ test and Pearson's correlation were used for continuous variables. Any value of $\mathrm{p}<0.05$ was considered significant.

Interobserver agreement between the clinical investigators and the US investigators and intraobserver US agreement were calculated using an unweighted $\kappa$ test. The $\kappa$ value measures agreement between pairs of observers, eliminating random concordance. A $\kappa$ value $<0.40$ was considered poor, 0.40-0.60 moderate, $0.60-0.80$ good, and $0.80-1$ excellent.

\section{RESULTS}

\section{Patients' characteristics}

Rheumatoid factor was positive in 73/94 (78\%) patients. Therapeutic regimens included non-steroidal anti-inflammatory drugs in $60(64 \%)$ patients, corticosteroids in $56(60 \%)$, methotrexate in 61 (65\%), leflunomide in $18(19 \%)$, sulfasalazine in $10(11 \%)$, antimalarial drugs in $10(11 \%)$, gold salts in $9(10 \%)$, infliximab in $8(9 \%)$, etanercept in 4 $(4 \%)$, ciclosporin in $2(2 \%)$, and azathioprine in $2(2 \%)$ patients. Two patients had a unilateral hip prosthesis, three patients a unilateral knee prosthesis, and one patient a bilateral hip and knee prosthesis. All surgical procedures had been performed more than 5 years before the study.
No significant differences were found between patients examined with scanners 1 and 2 for mean age, mean duration of symptoms, mean VASP and VASOA scores, mean joint count for tenderness and swelling, mean SJI, mean HAQ score and mean ESR and CRP values (table 2).

All joints, including nine prosthetic joints, could be easily assessed by US. The US examination took 20-30 minutes for each patient, not including documentation.

\section{Clinical and ultrasonographic joint involvement}

US detected more joints with effusion and synovitis than clinical examination. Mean (SD) USJCE was 15.2 (9.3), mean USJCS 14.6 (9.4), and mean SJC $11.5(7.4)(\mathrm{p}=0.003$ for mean USJCE $v$ mean SJC and $\mathrm{p}=0.01$ for mean USJCS $v$ mean SJC, respectively).

\section{Correlation between clinical, ultrasonographic, and laboratory variables}

VASP correlated highly with VASOA and HAQ $(r>0.6$, $\mathrm{p}<0.01)$. HAQ, VASP, and VASOA correlated weakly with ESR and CRP $(r<0.4, \mathrm{p}<0.05)$.

Table 3 shows the correlations between clinical, laboratory, and US variables. TJC, SJC, and SJI correlated poorly with HAQ, VASP, and VASOA $(\mathrm{p}<0.01)$. TJC did not correlate with ESR or CRP $(\mathrm{p}>0.05)$. SJC and SJI correlated poorly with ESR and moderately with CRP $(\mathrm{p}<0.01)$.

US joint count and index for effusion, synovitis, and PD signal correlated highly with CRP $(r>0.6, \mathrm{p}<0.01)$. US variables correlated moderately with ESR $(p<0.01)$, weakly with VASP, VASOA $(\mathrm{p}<0.05)$, and did not correlate with HAQ $(p>0.05)$. Disease duration did not correlate with any clinical, US, or laboratory variable $(\mathrm{p}>0.05)$ (data not shown).

Table 5 Clinical interobserver agreement

\begin{tabular}{llcc}
\hline & Tenderness & Swelling & Swelling index \\
\hline GH & $0.57(0.53$ to 0.61$)$ & 1.00 & 1.00 \\
ACL & $0.45(0.35$ to 0.54$)$ & 0.00 & 0.00 \\
SCL & $0.67(0.67$ to 0.67$)$ & $-0.01(-0.01$ to 0.01$)$ & $-0.01(-0.01$ to 0.01$)$ \\
ELB & $0.63(0.61$ to 0.65$)$ & $0.42(0.24$ to 0.59$)$ & $0.33(0.13$ to 0.52$)$ \\
WRS & $0.56(0.51$ to 0.60$)$ & $0.50(0.39$ to 0.60$)$ & $0.42(0.29$ to 0.54$)$ \\
HIP & $0.58(0.56$ to 0.60$)$ & $0.59(0.54$ to 0.63$)$ & $0.59(0.54$ to 0.63$)$ \\
KN & $0.68(0.65$ to 0.71$)$ & $0.46(0.43$ to 0.49$)$ & $0.37(0.34$ to 0.39$)$ \\
TBT & $0.53(0.51$ to 0.54$)$ & $0.39(0.36$ to 0.42$)$ & $0.29(0.27$ to 0.30$)$ \\
SBT & $0.38(0.36$ to 0.40$)$ & $0.27(0.15$ to 0.38$)$ & $0.27(0.15$ to 0.38$)$ \\
TRS & $0.57(0.51$ to 0.62$)$ & $0.24(-0.01$ to 0.48$)$ & $0.24(-0.01$ to 0.48$)$ \\
MCP & $0.61(0.52$ to 0.72$)$ & $0.36(0.17$ to 0.51$)$ & $0.30(0.18$ to 0.44$)$ \\
PIPH & $0.65(0.50$ to 0.80$)$ & $0.54(0.43$ to 0.65$)$ & $0.43(0.30$ to 0.55$)$ \\
MTP & $0.53(0.44$ to 0.61$)$ & $0.14(-0.02$ to 0.49$)$ & $0.20(-0.02$ to 1.00$)$ \\
PIPF & $0.38(0.26$ to 0.48$)$ & $0.18(0.00$ to 1.00$)$ & $0.18(0.00$ to 1.00$)$
\end{tabular}

Results are expressed as mean $\kappa$ values and range in parenthesis.

$\mathrm{GH}$, glenohumeral joint; $\mathrm{ACL}$, acromioclavicular joint; $\mathrm{SCL}$, sternoclavicular joint; $E L B$, elbow joint; WRS, wrist joint; KN, knee joint; TBT, tibiotalar joint; SBT, subtalar joint; TRS, mid-tarsal joint; MCP, metacarpophalangeal joint; PIPH, proximal interphalangeal joint of hands; MTP, metatarsophalangeal joint; PIPF, proximal interphalangeal joint of feet. 
Table 6 Ultrasonographic intraobserver and interobserver agreement

\begin{tabular}{|c|c|c|c|c|c|c|}
\hline \multirow[b]{2}{*}{ Joint } & \multicolumn{2}{|l|}{ Effusion } & \multicolumn{2}{|l|}{ Synovitis } & \multicolumn{2}{|l|}{ PD signal } \\
\hline & Intra & Inter & Intra & Inter & Intra & Inter \\
\hline $\mathrm{GH}$ & 0.78 & 1.00 & 1.00 & 0.48 & 1.00 & 1.00 \\
\hline $\mathrm{ACL}$ & 0.68 & 0.83 & 0.76 & 0.59 & 0.75 & 0.84 \\
\hline $\mathrm{SCL}$ & 0.90 & 0.90 & 0.79 & 0.46 & 0.82 & 0.82 \\
\hline ELB & 1.00 & 0.94 & 0.76 & 0.76 & 1.00 & 0.79 \\
\hline WRS & 0.59 & 0.73 & 0.62 & 0.41 & 0.71 & 0.69 \\
\hline HIP & 0.89 & 1.00 & 0.88 & 0.67 & 0.88 & 1.00 \\
\hline $\mathrm{KN}$ & 1.00 & 0.96 & 0.91 & 0.77 & 0.93 & 0.86 \\
\hline TBT & 0.77 & 0.83 & 0.91 & 0.75 & 1.00 & 1.00 \\
\hline SBT & 0.64 & 0.82 & 1.00 & 1.00 & 1.00 & 1.00 \\
\hline TRS & 0.88 & 0.94 & 0.94 & 0.83 & 0.84 & 0.83 \\
\hline MCP & $0.83(0.75-0.95)$ & $0.81(0.76-0.95)$ & $0.76(0.74-0.85)$ & $0.75(0.65-0.84)$ & $0.90(0.82-1.00)$ & $0.88(0.81-1.00)$ \\
\hline $\mathrm{PIPH}$ & $0.79(0.59-0.93)$ & $0.84(0.66-1.00)$ & $0.80(0.74-0.85)$ & $0.77(0.48-1.00)$ & $0.89(0.75-1.00)$ & $0.79(0.74-0.90)$ \\
\hline MTPI & $0.86(0.81-0.92)$ & $0.81(0.71-0.92)$ & $0.81(0.71-0.92)$ & $0.78(0.65-0.95)$ & $0.90(0.80-1.00)$ & $0.88(0.80-1.00)$ \\
\hline PIPF & $0.88(0.74-1.00)$ & $0.83(0.58-1.00)$ & $0.89(0.65-1.00)$ & $0.86(0.65-1.00)$ & $0.90(0.74-1.00)$ & $0.89(0.73-1.00)$ \\
\hline
\end{tabular}

Results are expressed as $\kappa$ values or mean $\kappa$ plus range in parenthesis when several joints were affected.

For abbreviations see footnote to table 5 .

TJC and SJC correlated weakly $(r=0.49, \mathrm{p}<0.01)$. TJC did not correlate with joint count for US effusion, US synovitis, and PD signal $(\mathrm{p}>0.05)$. SJC correlated with US joint counts $(r=0.58,0.57$, and 0.56 , respectively, $\mathrm{p}<0.01)$. Correlations between SJI and US index for effusion, synovitis, and PD signal were better $(r=0.65,0.64$, and 0.58 , respectively, $\mathrm{p}<0.01)$. A high correlation $(r>0.80, \mathrm{p}<0.01)$ was found between all the US variables.

TJC and SJC correlated highly with TJC28 $(r=0.95$, $\mathrm{p}<0.01)$ and SJC28 $(r=0.96, \mathrm{p}<0.01)$. In the same way, there was a high correlation between USJCE and USJCE2 8 $(r=0.92, \mathrm{p}<0.01)$, USJCS and USJCS28 $(r=0.92, \mathrm{p}<0.01)$, and between USJCPD and USJCPD28 $(r=0.94, \mathrm{p}<0.01)$. USJCE28, USJCS28, and USJCPD28 showed similar correlations with clinical and laboratory measures as with the corresponding 60 joint counts (table 3 ).

For the 69 patients examined with scanner l, US findings showed a similar correlation with clinical and laboratory measures as those obtained in the overall group (table 4). There was a high correlation between US parameters and CRP levels $(\mathrm{p}<0.01)$.

\section{Clinical and ultrasonographic reliability}

Clinical interobserver agreement ranged from poor to excellent (table 5). Overall interobserver agreement for tenderness was better than for swelling and for the swelling index. There was a high level of intraobserver and interobserver agreement, from moderate to excellent, for US effusion, synovitis, and PD signal (table 6).

\section{DISCUSSION}

We found that US was clearly more sensitive than physical examination in detecting joint swelling. In addition, US findings correlated better with CRP and ESR than clinical joint swelling. In keeping with our results, other studies have demonstrated that US detects subclinical synovitis. ${ }^{42} 43$ Because therapeutic decisions depend considerably on clinical synovitis, the undetectable synovitis may explain the continued bone damage found in patients with clinically controlled RA. In the same way, the results of Jevtic et al confirmed that in joints with inflammatory active pannus detected by contrast enhanced MRI, progression of bonedestructive changes is expected. ${ }^{44}$

Hypervascularisation and angiogenesis of the synovial membrane are considered to be primary pathogenic mechanisms responsible for invasive and joint destructive behaviour of rheumatoid pannus. ${ }^{45-47}$ Dynamic contrast enhanced MRI findings have demonstrated a close correlation with histological signs of knee synovial inflammation in patients with RA. ${ }^{48}{ }^{49}$ However MRI is expensive, time consuming, and not widely available for routine use in most countries. Recently, PD US has demonstrated a high sensitivity (88.8\%) and specificity (97.9\%) for the assessment of inflammatory activity in the MCP joints of patients with RA compared with dynamic contrast enhanced MRI. ${ }^{50}$ One advantage of US over MRI is that examination of all peripheral joints can be done as many times as required and prosthesis or implants do not interfere with US images. Last but not least, rheumatologists can be trained to perform US, removing the need for referral to a radiologist and thus saving time and money.

US variables correlated with clinical joint swelling, CRP, and ESR, correlated weakly with VAS scales, and did not correlate with clinical joint tenderness and HAQ. Previous studies comparing clinical and US assessment have also reported a stronger correlation between US and physical examination of joint swelling than between US findings and patient's perception of joint tenderness. ${ }^{17} 26$ Furthermore, Qvistgaard et al found that the degree of synovial vascularisation in finger joints detected by colour Doppler correlated with ESR, and not with VAS for pain, VAS for patient overall assessment, and HAQ scores in patients with RA. ${ }^{26}$ In fact, joint tenderness, VAS scales, and HAQ scores indicate either disease activity or structural joint damage or deformity secondary to previous synovial inflammation not present when clinical evaluation is performed.

This study evaluated 60 joints in each patient with RA, whereas similar previous reports investigated only a small number of joints, such as knee, MCP, and PIP joints. ${ }^{3-33}$ We considered that 60 joint counts represented an overall assessment of disease inflammatory activity. However, reduced joint counts for tenderness and swelling, such as the 28 joint count ${ }^{41}$ are widely used in the evaluation of RA inflammatory activity in daily practice and in clinical trials. Our 28 joint count for US effusion, synovitis, and PD signal correlated well with the 60 joint count. Thus, the reduced joint count could be used in US evaluation in rheumatological practice. Although effusion and synovitis can also be seen in other periarticular locations of the examined joints, we performed a simplified US investigation in order to shorten scanning duration. The proposed US evaluation of 28 joints can be performed in 15 minutes in daily practice.

Recent studies have reported the validity ${ }^{50}$ and reliability ${ }^{51}$ of cheaper US machines for assessing rheumatoid synovial inflammation, though most reports have used expensive machines like our scanner 2. ${ }^{31-35}$ Analysis of the results from scanner 1 showed that they were comparable with the overall 
results. Therefore, a considerably more affordable machine like scanner 1 could also be used.

Some limitations of our study should be mentioned. The assessment of a single selected US image instead of a real time examination of the joints performed by the second rheumatologist obviously introduces bias into the study. However, this is the standard way to record US examination in daily practice and the images for a second reading were chosen by an experienced sonographer. Our data are in accordance with those of Szkudlarek et al, who recently reported a high interobserver agreement for the identification and semiquantitative measurement of effusion, synovitis, and PD signal in the small joints of patients with RA. ${ }^{51}$ In addition, the rheumatologist obtaining the sonograms could not be completely unaware of a patient's joint signs and symptoms. To avoid as much bias as possible, the US examination was carried out in the dark.

A number of factors potentially limit the use of PD. Firstly, no examination protocols or standard settings for PD US machines exist. In addition, PD US is extremely sensitive to tissue movement, especially at low PRF, which can result in "flash" artefacts. However, we used pulsed Doppler spectra as proof of the presence of vessels when images were doubtful.

\section{CONCLUSION}

We propose that the combination of grey scale US and PD could be used as a sensitive and reliable non-invasive and widely available method complementary to standard clinical assessment for evaluating rheumatoid synovial inflammation in daily management and clinical trials. Moreover, images of the examinations performed can be kept. PD may become a cost effective alternative to gadolinium enhanced MRI. Longitudinal studies that correlate PD findings with long term clinical changes and radiographic erosive joint damage in patients with RA are highly warranted.

\section{ACKNOWLEDGEMENTS}

We thank the staff members of the Department of Rheumatology, Hospital de la Princesa, Madrid, Spain; Alvaro-Gracia JM, MD; Castañeda S, MD; García-Vadillo A, MD; García de Vicuña R, MD; González-Alvaro I, MD; López-Bote JP, MD; Humbría A, MD; Ortiz A, $\mathrm{MD}$; Bascones $\mathrm{M}, \mathrm{MD}$ and Tomero $\mathrm{E}, \mathrm{MD}$; for allowing us to study their patients. We also thank Mr R Cuadrado, Mr J Gálvez, Mr A Escribano, and Mr LA Ortega, from General Electric Medical Systems Corporation for their technical support.

This study was supported by a grant from Schering-Plough.

\section{Authors' affiliations}

E Naredo, G Bonilla, F Gamero, J Uson, A Laffon, Department of Rheumatology, Hospital de la Princesa, Madrid, Spain

L Carmona, Research Unit, Hospital de la Princesa, Madrid, Spain

The second and third authors contributed equally to the study.

\section{REFERENCES}

1 ACR. American College of Rheumatology Ad Hoc Committee on Clinical Guidelines. Guidelines for the management of Rheumatoid Arthritis. Arthritis Rheum 1996;39:713-22.

2 Van der Heijde DMFM, van't Hof MA, van Riel PLCM, van de Putte LBA. Development of a disease activity score based on judgment in clinical practice by rheumatologists. J Rheumatol 1993;20:579-81.

3 Felson DT, Anderson JJ, Boers M, Bombardier C, Chernoff M, Fried B, et al. The American College of Rheumatology preliminary core set of disease activity measures for rheumatoid arthritis clinical trials. Arthritis Rheum 1993;36:729-40

4 Proceedings from the Conference on Outcome Measures in Rheumatoid Arthritis Clinical Trials (OMERACT). J Rheumatol 1993;20:526-91.

5 Eberl DR, Fasching V, Rahlfs V, Schleyer I, Wolf R. Repeatability and objectivity of various measurements in rheumatoid arthritis. A comparative study. Arthritis Rheum 1976;19:1278-86.

6 Grassi W, Cervini C. Ultrasonography in rheumatology: an evolving technique. Ann Rheum Dis 1998;57:268-70.
7 Koski JM, Anttila PJ, Hämäläinen M, Somäki H. Hip joint ultrasonography: correlation with intraarticular effusion and synovitis. Br J Rheumatol 1990;29:189-92

8 Grassi W, Tittarelli E, Pirani O, Avaltroni D, Cervini C. Ultrasound examination of metacarpophalangeal joints in rheumatoid arthritis. Scand J Rheumatol 1993;22:243-7.

9 Alasaarela EM, Alasaarela ELI. Ultrasound evaluation of painful rheumatoid shoulders. J Rheumatol 1994;21:1642-8.

10 Ostergaard M, Court-Payen M, Gideon P, Wieslander S, Cortsen M, Lorenzen I, et al. Ultrasonography in arthritis of the knee. A comparison with MR imaging. Acta Radiol 1995;36:19-26.

11 Lund PJ, Heikal A, Maricic MJ, Krupinski EA, Williams CS. Ultrasonographic imaging of the hand and wrist in rheumatoid arthritis. Skeletal Radiol 1995;24:591-6.

12 Alasaarela E, Tervonen O, Takalo R, Lahde S, Suramo I. Ultrasound evaluation of the acromioclavicular joint. J Rheumatol 1997;24:1959-63.

13 De Maeseneer M, Jacobson JA, Jaovisidha S. Elbow effusion. Distribution of joint fluid with flexion and extension and imaging implications. Invest Radiol 1998; 33: 117-25

14 Jacobson JA, Andresen R, Jaovisidha S, De Maeseneer M, Foldes K, Trudell DR, et al. Detection of ankle effusion: comparison study in cadavers using radiography, sonography and MR imaging. AJR Am J Roentgenol 1998; 170:1231-8

15 Alasaarela E, Leppilahti J, Hakala M. Ultrasound and operative evaluation of arthitic shoulder joints. Ann Rheum Dis 1998;57:357-60.

16 lagnocco A, Coari G. Usefulness of high resolution US in the evaluation of effusion in osteoarthritic first carpometacarpal joint. Scand J Rheumatol 2000;29:170-3.

17 Backhaus M, Kamradt T, Sandrock D, Loreck D, Fritz J, Wolf KJ, et al. Arthritis of the finger joints. A comprehensive approach comparing conventional radiography, scintigraphy, ultrasound and contrast-enhanced magnetic resonance imaging. Arthritis Rheum 1999;42:1232-45.

18 Gratz S, Göbel D, Max Behr T, Herrmann A, Becker W. Correlation berween radiation dose, synovial thickness and efficacy of radiosynoviorthesis. J Rheumatol 1999;26:1242-9.

19 Van Holsbeeck M, Van Holsbeeck K, Gevers G, Marchal G, van Steen A, Favril A, et al. Staging and follow-up of rheumatoid arthritis of the knee. $J$ Ultrasound Med 1988;7:561-6.

20 Rubaltelli L, Fiocco U, Cozzi L, Baldovin M, Rigon C, Bortoletto P, et al. Prospective sonographic and arthroscopic evaluation of proliferative knee synovitis. J Ultrasound Med 1994;13:855-62.

21 Fiocco U, Cozzi L, Rubaltelli L, Rigon C, De Candia A, Tregnaghi A, et al. Long-term sonographic follow-up of rheumatoid and psoriatic proliferative knee joint synovitis. Br J Rheumatol 1996;35:155-63.

22 Karim Z, Wakefield RJ, Quinn M, Conaghan PG, Brown AK, Veale DJ, et al. Validation and reproducibility of ultrasonography in the detection of synovitis in the knee. Arthritis Rheum 2004;50:387-94.

23 Eberhardt K, Fex E, Johnsson K, Geborek P. Hip involvement in early rheumatoid arthritis. Ann Rheum Dis 1995;54:45-8.

24 Hauzeur EP, Mathy L, De Maertelaer V. Comparison between clinical evaluation and ultrasonography in detecting hydrathrosis of the knee. J Rheumatol 1999:26:2681-3.

25 Kane D, Balint PV, Sturrock RD. Ultrasonography is superior to clinical examination in the detection and localization of knee joint effusion in rheumatoid arthritis. J Rheumatol 2003;30:966-71

26 Qvistgaard E, Rogind H, Torp-Pedersen S, Terslev L, Danneskiold-Samsoe B, Bliddal $\mathrm{H}$. Quantitative ultrasonography in rheumatoid arthritis: evaluation of inflammation by Doppler technique. Ann Rheum Dis 2001;60:690-3.

27 Murphy KJ, Rubin JM. Power Doppler: it's a good thing. Semin Ultrasound, CT, MRI 1997;18:13-21.

28 Martinoli C, Pretolesi F, Crespi G, Bianchi S, Gandolfo N, Valle M, et al. Power Doppler sonography: clinical applications. Eur J Radiol 1998;28: 133-40.

29 Newman JS, Adler RS, Bude RO, Rubin JM. Detection of soft-tissue hyperemia: value of power Doppler sonography. AJR Am J Roentgenol 1994; 163:385-9.

30 D'Agostino MA, Said-Nahal R, Hacquard-Bouder C, Brasseur JL, Dougados $M$, Breban M. Assessment of peripheral enthesitis in the spondylarthropathies by ultrasonography combined with power Doppler. Arthritis Rheum 2003;48:523-33.

31 Newman JS, Laing TJ, McCarthy CJ, Adler RS. Power Doppler sonography of synovitis: assessment of therapeutic response. Preliminary observations. Radiology 1996; 198:582-4.

32 Hau M, Schultz H, Tony HP, Keberle M, Jahns R, Haerten R, et al. Evaluation of pannus and vascularization of the metacarpophalangeal and proximal interphalangeal joints in rheumatoid arthritis by high-resolution ultrasound (multidimensional linear array). Arthritis Rheum 1999:42:2303-8.

33 Schmidt WA, Völker L, Zacher J, Schläfke M, Ruhnke M, Grommica-Ihle E. Colour Doppler ultrasonography to detect pannus in knee joint synovitis. Clin Exp Rheumatol 2000;18:439-44.

34 Walther M, Harms H, Krenn V, Radke S, Faehndrich TP, Gohlke F. Correlation of power Doppler sonography with vascularity of the synovial tissue of the knee joint in patients with osteoarthritis and rheumatoid arthritis. Arthritis Rheum 2001;44:331-8.

35 Walther M, Harms H, Krenn V, Radke S, Kirschner S, Gohike F. Synovial tissue of the hip at power Doppler US: Correlation betwenn vascularity and power Doppler US signal. Radiology 2002;225:225-31.

36 Arnett FC, Edworthy SM, Bloch DA, McShane DJ, Fries JF, Cooper NS, et al. The American Rheumatism Association 1987 revised criteria for the classification of rheumatoid arthritis. Arthritis Rheum 1988;31:315-24. 
37 Esteve-Vives J, Batlle-Gualda E, Reig A. Spanish version of the Health Assessment Questionnaire: reliability, validity and transcultural equivalency. J Rheumatol 1993;20:2116-22.

38 Koski JM. Ultrasonography of the elbow joint. Rheumatol Int 1990;10:91-4.

39 Nazarian LN, Rawool NM, Martin CE, Schweitzer ME. Synovial fluid in the hindfoot and ankle: detection of amount and distribution with US. Radiology 1995; 197:275-8.

40 Koski JM, Hermunen $\mathrm{H}$. Intra-articular glucocorticoid treatment of the rheumatoid wrist. An ultrasonographic study. Scand J Rheumatol 2001;30:268-70

41 Smolen JS, Breedveld FC, Eberl G, Jones I, Leeming M, Wylie GL, et al. Validity and reliability of the twenty-eight-joint count for the assessment of rheumatoid arthritis activity. Arthritis Rheum 1995:38:38-43.

42 Karim Z, Wakefield RJ, Conaghan PG, Lawson CA, Goh E, Quinn MA, et al. The impact of ultrasonography on diagnosis and management of patients with musculoskeletal conditions. Arthritis Rheum 2001;44:2932-3.

43 Wakefield RJ, Green MJ, Marzo-Ortega H, Conaghan PG, Gibbon WW, McGonagle D, et al. Should oligoarthritis be reclassified? Ultrasound reveals a high prevalence of subclinical disease. Ann Rheum Dis 2004;63:382-5.

44 Jevtic V, Vatt I, Rozman B, Presetnik M, Logar D, Praprotnik S, et al. Prognostic value of contrast enhanced Gd-DTPA MRI for development of bone erosive changes in rheumatoid arthritis. Br J Rheumatol 1996;35(suppl 3):26-30.
45 FitzGerald O, Bresnihan B. Synovial membrane and vascularity. Ann Rheum Dis 1995;54:511-15.

46 Koch AE. Review: angiogenesis: implications for rheumatoid arthritis. Arthritis Rheum 1998:41:951-62.

47 Maini RN, Taylor PC, Paleolog E, Charles P, Ballara S, Brennan FM, et al. Anti-Tumor necrosis factor specific antibody (infliximab) treatment provides insights into the pathophysiology of rheumatoid arthritis. Ann Rheum Dis 1999;58(Suppl I):i56-60.

48 Gaffney K, Cookson J, Blake D, Coumbe A, Blades S. Quantification of rheumatoid synovitis by magnetic resonance imaging. Arthritis Rheum 1995;38:1610-17.

49 Gaffney K, Cookson J, Blake D, Coumbe A, Blades S. Quantiffative assessment of the rheumatoid synovial microvascular bed by gadoliniumDTPA enhanced magnetic resonance imaging. Ann Rheum Dis 1998;57:152-7.

50 Szkudlarek M, Court-Payen M, Stranberg C, Klarlund M, Klausen T, Ostergaard $M$. Power Doppler ultrasonography for assessment of synovitis in the metacarpophalangeal joints of patients with rheumatoid arthritis. A comparison with dynamic magnetic resonance imaging. Arthritis Rheum 2001;44:2018-23.

51 Szkudlarek M, Court-Payen M, Jacobsen S, Klarlund M, Thomsen HS, Ostergaard $M$. Interobserver agreement in ultrasonography of the finger and toe joints in rheumatoid arthritis. Arthritis Rheum 2003;48:955-62. 